\title{
Accepted for publication
}

Hussein, S. (in Press) International Journal of Care and Caring

Job demand, control and unresolved stress within the emotional work of long term care in

England

\begin{abstract}
Long-term care (LTC) work is known for its difficult working conditions with potential implications on workers' wellbeing. In England LTC policies are moving progressively towards marketisation, while public social care funding is under considerable strain. Little evidence exists on the job demand and control of LTC workers who provide personal and direct care to adults and older people. The article uses survey data from LTC workers in England ( $n=991)$ to examine the levels of, and differentials in, job strain among LTC workers. The findings highlight the vulnerability of certain groups of workers with potential negative impact on their wellbeing.
\end{abstract}

Keywords: Karasek Job Demand and Control Model; work stress models; marketisation; workers' vulnerability

\section{Introduction}

Long term care (LTC) workers provide intimate and personal care to older people and adults with long-term disabilities or care needs in care homes, people's own homes (homecare) and the community. Much formal care - that is, care paid for and provided by trained care staff for older people and others with LTC needs is provided by frontline care workers, working in care homes, homecare or in settings such as day centres. The sector's workforce also includes professionally qualified staff, such as registered nurses, social workers and occupational therapists; managers and supervisors, and an array of ancillary staff providing non-direct care 
services, such as cleaning, driving and catering (SfC, 2016). Overall, the LTC sector is estimated to encompass over two million jobs in the UK (SfC, 2016), comprising six per cent of the total labour force [an estimated 32 million people are in employment in the UK, Office for National Statistics, 2017)]. The workforce is characterised by its gendered nature and reliance on migrant workers who as a consequence of their transnational status may lack social capital.

LTC work is also known for its difficult working conditions, poor pay and persistent high turnover rates (Hussein, Ismail and Manthorpe,, 2016, Hussein, 2017a; Rubery et al, 2011). Recent studies have shown increased fragmentation of care provision, a decline in the support mechanisms available to the workforce and (associated with an overall decline in the level of protection and employment rights offered to care workers) the expansion of zero-hour contracts (Cary, 2014; Rubery et al, 2015; SfC, 2016). England was one of the first European countries to adopt a marketisation policy of care provision combined with a broader agenda of personalisation (Colombo et al, 2011; Himmelweit, 2014). Policy developments, including personalisation and the marketisation of care delivery, have (arguably) led to increased levels of precarious working arrangements, casualisation and job insecurity (Anderson and Hughes, 2010; McGann et al, 2016). Evidence of increased casualisation and fragmentation of care work is significant when considering a sector that continues to rely on 'vulnerable workers', especially women with lower skill levels and migrants (Baines and Cunningham, 2011).

In addition to these challenging structural conditions, care work itself is regarded as emotionally taxing (Brotheridge and Grandey, 2002) with the regulation of feelings and expressions at work a critical aspect of care workers' performance. Overall, research demonstrates that job stress, as an aspect of emotional labour, can have serious implications for the health and wellbeing of this group of workers, who deal with some of the most 
vulnerable people in society, including older people with dementia and people with severe learning disabilities (Spenceley et al, 2015; Varcoe et al, 2012).

As demand for LTC increases due to population ageing and wider social changes, the challenges facing the formal care workforce are increasingly acknowledged (Yeandle et al, 2017). There remains a paucity of research on the psychological wellbeing of LTC workers, despite ongoing attention to emotional burnout, job demand and emotional distress among human services' practitioners (Maslach and Jackson, 1984). The majority of UK studies of these topics focus on professionally qualified staff such as social workers (Hussein et al., 2014a and 2014b; Manthorpe et al, 2014), mental health professionals (Evans et al, 2006) and nurses (Gama et al, 2014; Skirrow and Hatton, 2007; Woodhead et al, 2016), with relatively few studies focusing on LTC workers who provide direct or hands-on personal and emotional support to a variety of care users (Wilberforce et al, 2014).

One of the most influential models in organisational psychology research linking work and health is the Job Demand-Control (JDC) model, also known as the job strain model (Karasek et al, 1998). The JDC model identifies two crucial job aspects in the work situation: 'job demands' and 'job control'. The model specifies that job strain is not the result of either of these work environment aspects alone, but the interactive effect of the two. According to the JDC model, having higher decision latitude over the work process reduces a worker's stress but increases learning; whereas psychological demands increase learning as well as stress. These two mechanisms are represented by the diagonals of the model (Figure 1); following the 'strain' diagonal, the 'strain' hypothesis states that the most adverse reactions of psychological strain and physical illness are expected in a 'high-strain' job experience, that is, in a high demands / low control job. On the other hand, following the 'learning' diagonal, a second hypothesis states that high demands in combination with high control lead to increased learning, motivation and the development of skills, representing an 'active' job experience. 
High job strain has been found to be associated with several health outcomes, notably cardiovascular disease (Hallqvist et al, 1998; Landsbergis and Theorell, 1999); work-related musculoskeletal disorders (Hoogendoorn et al, 2000); and workers' general wellbeing (Warr, 1990). It has also been found to be associated with early retirement among health and social care employees (Elovainio et al, 2005).

Karasek and Theorell (1990) re-conceptualised the JDC model to include social support as a mitigating factor when high psychological job demand is not matched with enough decision autonomy. In this model, social support consists of two domains: supervisor support and coworker support. Some studies have shown that a high level of social support (particularly coworker support) has positive implications for work outcomes, such as job satisfaction, burnout, de-personalisation and work performance (Sargent and Terry, 2000; Woodhead et al, 2016). On the other hand, in previous literature the significance of social support in reducing negative implications for workers' wellbeing is inconclusive (Bakker and Demerouti, 2007; Van der Doef and Maes, 1999).

**** Figure 1 around here $* * * *$

In this article, we use the JDC model as a framework to understand the levels of job strain among LTC workers, using empirical data from a large study of care workers in England. We are particularly interested in inter-occupation variations, their relationship with key personal and workplace factors, and how they influence levels of job strain and insecurity. This is particularly important when considering current challenges and changes in the broader system and organisational structure of LTC provision in England. The specific aim of the study is to establish the prevalence of high strain job experience among LTC workers, and to identify key protective and risk factors. 


\section{Data and Methods}

\section{Study description}

The analysis presented here uses data from the Longitudinal Care Work Study (LoCS) which adopted a longitudinal data collection design with the aim of achieving a locally representative sample of LTC employers in four different parts of England, across the statutory (public), voluntary and private /independent sectors. In each site, nested samples of 15 agencies (across these three sectors), drawn from a sampling frame of all care providers in these areas, were acquired from the Care Quality Commission's (CQC) list of services and recruited into the study. The same sample of providers participated in the study at two time points (T1: 2010-11 and T2: 2012-13). Invitations to participate in a repeated online survey were distributed (by their employers) to all employees in the selected organisations. As the research team was (in some cases) unable to identify if the same individuals responded to the surveys at the two different time points, the data on employees in this study forms a repeated cross-sectional sample. The mixed-method design of the LoCS study included a repeated survey for employees $(n=1,342)$ and repeated interviews with employers / managers, frontline staff and users and carers $(n=300)$. Ethical approval was obtained from King's College London and research governance agreement from the four participating local councils; the research was funded by the English Department of Health and Social Care.

The employees' survey collected information on work history, working conditions and future plans. It also included the Karasek Job Content Questionnaire (JCQ), a self-completion instrument designed to identify job demands (the stressors existing in the work environment) and job decision latitude [job control - the extent to which employees have the potential to control their tasks and conduct throughout the working day] (Karasek et al, 1998). Decision 
latitude includes two components: skill discretion and decision authority. The JCQ also collects data using standardised scales on the level of support received from co-workers and supervisors, which is summed to provide an overall measure of social support at work, and a measure of job insecurity. Social support was measured using eight questions (four related to supervisor support, while job insecurity was measured using the three elements proposed by Karasek: how steady is the work; how the job security is judged by the individual; and how likely the individual is to lose their job within the next two years. (For a full list of questions see Karasek,, 1985).

\section{Participants' profile}

The current analysis uses a sub-sample of the first two waves of the employees' survey (T1 and T2), which includes those who identified the nature of their work as 'mostly hands-on care' or 'mainly hands-on care with some administrative tasks' $(n=991)$. Table 1 provides a breakdown of the survey sample by key characteristics.

$* * *$ Table 1 around here $* * *$

\section{Methods}

A two-step analysis was undertaken: first, we examined the scores of various components of the Karasek JCQ according to LTC workers' key personal and workplace characteristics by considering differences in the mean scores of job demand, decision latitude, job insecurity and social support. All Karasek scales showed good internal consistency, according to Cronbach's alpha [decision latitude $(\alpha=0.83)$; psychological job demand ( $\alpha=0.77)$; and social support $(\alpha=0.86)]$. Secondly, to examine how LTC workers are distributed within the quantum of job demand and control scales, we classified our sample according to the 
theoretical Karasek JDC model presented in Figure 1, using the social services standards score as determined by Karasek (1985) as the average scores for this occupation (decision latitude $=71.9$ and psychological job demand $=32$ ). Using these average scores, we classified our sample into four groups, representing the four quadrants in Figure 1:

1. 'Low strain' job experience: with scores for job demand below and job control above the occupational average;

2. 'Passive' job experience: with scores for both job demand and job control below the occupational average;

3. 'Active' job experience: with scores for both job demand and job control above the occupational average; and

4. 'High strain' job experience: with scores for job demand above and job control below the occupational average.

We first examined the characteristics of each of the four groups of workers, including the level of social support in the workplace and personal and workplace characteristics. To understand which factors are associated with experiencing each of these job quadrants, with a specific focus on the 'high strain' experience, we constructed a multinomial regression model which serves our purpose of comparing the profile of LTC workers with different demandcontrol job experiences simultaneously. Time effect was accounted for by including the survey time point as an independent variable for analyses to assess whether or not there were changes in job demand and control over time. Prior to conducting the analysis, a careful inspection of the dataset revealed its suitability for multinomial logistic regression estimation, and the analysis was conducted using Stata ver. 12.

We used the group of workers representing the 'low strain' job experience as the comparison group for the dependent variable in the multinomial regression model. We included the 
following individual and workplace characteristics as independent variables for the model: workers' gender; ethnicity (White vs. Black and Ethnic Minority [BME]); Nationality (British vs. migrant); perception of their own financial situation in the previous 12 months (1- living comfortably; 2 - doing alright / just about managing; 3 - finding finances difficult / very difficult to manage); age; nature of work (1- all or mostly hands-on care work; 2- mainly hands-on care with some administrative tasks [comb.]); belonging to a trade union (yes vs. no); main place of work (care home vs. other, and homecare vs. other); level of social support in the workplace; and time.

\section{Results}

Psychological job demand, decision latitude, social support and job insecurity among LTC workers

Tables 2 and 3 present the Karasek JCQ scales by care workers' individual and work characteristics, as derived from their responses to LoCS staff survey. On average, participants scored 70.3 on the decision latitude scale (control), 34.5 on the psychological job demand scale (demand); 5.9 on job insecurity scale and 24.4 on the social support scale. The analysis indicates that scores in some of these scales varied significantly by certain individual and work characteristics. Table 2 shows that those who found their personal financial situation 'difficult' or 'very difficult' to manage (a proxy to reflect poverty pay) displayed significantly lower levels of job control $(F=5.39, p<0.001)$.

$* * * *$ Table 2 around here $* * * *$

Table 3 shows that the nature of the work was significantly associated with all the JCQ subscales, except social support at work. Both job demand and job control were significantly 
lower among workers whose job was 'all or mostly hands on care' compared with those who provided a combination of care and administrative work $(F=73.61, p<0.001 ; F=4.85$, $p=0.028)$. At the same time, job insecurity levels were lower among the same group of workers $(F=4.65 ; p=0.033)$.

$* * * *$ Table 3 around here $* * * *$

Trade union membership was significantly associated with all of the JCQ sub-scales, with trade union members displaying higher levels of job demand and control and job insecurity, combined with lower levels of social support $(F=142.68, p<0.001 ; F=10.16, p=0.001$; $F=14.04, p<0.001$ and $F=13.46, p<0.001$ respectively). Primary place of work was also significantly associated with most of the scales examined. Workers employed primarily in care homes displayed significantly lower job insecurity levels, compared with the rest of the sample, while those working in homecare displayed significantly higher levels of job control, job demand and job insecurity than others in the sample.

\section{JDC model and job experience classification}

In this analysis we specifically focused on the JDC model (as explained in the Methods section). The model postulates job strain as the result of an interaction between demand and control, meaning that a job with high demand and low control would be labelled as 'high strain', while a job with low demand and high control would be viewed as 'low strain'. Within such a relationship, the level of 'social support' received at work plays a significant role. Social support is theorised to moderate or 'buffer' the impact of job-related stress; in particular, individuals in high stressor jobs will have lower psychological strain in the presence of social support. Figure 2 presents a scatter diagram of LoCS sample, distributed by the decision latitude (control) and psychological job demand scores. Participants were 
classified into four groups, representing low strain, active, passive and high strain job experiences, within the LTC occupation.

$* * * *$ Figure 2 around here $* * * *$

Table 4 presents the distribution of LTC workers according to these four quadrants by different worker and workplace characteristics: survey time point; age; place of work; nature of work; trade union membership; and ability to manage own finances all appeared to be associated with the position of workers within the JDC model. Among our sample of LTC workers, $13.2 \%$ fell into the 'low strain' job quadrant; $18.6 \%$ into the 'passive'; $32.9 \%$ into the 'active job' quadrant; and 35.3\% into the 'high strain' quadrant. Some characteristics, such as survey time point, age, working in homecare, nature of work, and belonging to a trade union, as well as the level of social support received at work, were significantly different across the four quadrants of the JDC model. Social support was lowest among LTC workers experiencing high strain jobs (22.9 compared with 24.4 for the total sample).

$* * * *$ Table 4 around here $* * * *$

To identify the variables significantly associated with having specific job experiences (low strain, passive, active or high strain), while accounting for the effect of other characteristics, we performed a multinomial regression analysis. The results of this are presented in Table 5 . One of the main findings relates to how social support at work is associated with the position of workers within the model, with those receiving higher levels of social support significantly more likely to have low strain job experiences, and less likely to have high strain job experiences. Workers who perform mostly hands-on care were significantly less likely to have high strain job experiences $(\mathrm{OR}=0.47, p=0.005)$, compared with those providing a combination of hands-on care and administrative tasks. Workers who indicated that they were able to manage their finances 'well' or 'alright' were less likely to have a passive or high 
strain job experience $(\mathrm{OR}=0.35 ; p=0.007$ and $\mathrm{OR} 0.53, p=0.05$ respectively). Care home workers (working in residential or nursing homes) were more likely to have high strain jobs at borderline significance $(\mathrm{OR}=1.70, p=0.065)$. Those who responded at Time 2 of the survey were more likely to have either active or high strain jobs, compared with Time 1 respondents $(\mathrm{OR}=2.17, p=0.008$ and $\mathrm{OR}=1.69, \mathrm{p}=0.079$ respectively $)$. Workers who were members of a trade union were significantly more likely to have active or high strain jobs $(\mathrm{OR}=4.64$, $p<0.001$ and $\mathrm{OR}=2.86, p<0.001$ respectively). None of the workers' personal characteristics, except age, had a significant association with their position within the JDC model.

$* * * *$ Table 5 around here $* * * *$

\section{Discussion}

Employing the standardised JCQ (Karasek et al, 1998) we identified the levels of job demand and control; in-work social support and job insecurity among a large sample of LTC workers in England. LTC workers' participating in this study scored on average 70 on the decision latitude scale (control), 34 on the psychological job demand scale (demand), 5.9 on the job insecurity scale and 24.4 on the social support scale. Within the literature, only one study employing similar measures was identified (Wilberforce et al., 2014); this focused primarily on less qualified care workers in England and on LTC workers employed as personal assistants to care users with personal budgets. The findings of our study resonate with those of Wilberforce and colleagues, with LTC workers participating in LoCS scoring similarly on the decision latitude scale (70 compared with 69.5); lower on the psychological job demand scale (34 compared with 37.2 ) and similarly on the social support scale (24.4 compared with 25). While Wilberforce et al (2014) did not report scores for job insecurity among their sample, the average observed in our study (5.9) is slightly higher than that for child protection 
social workers, and is very close to that observed among social workers working with adults in England (Hussein et al., 2014a; Manthorpe et al, 2014).

The analysis presented here shows that none of the workers' individual characteristics had a significant association with any of the JCQ scores. Nor did other factors, such as nationality and ethnicity, show any significant associations. One of the key factors observed to have a significant relationship on most of the JCQ scales was how well individual workers felt they were able to manage their own finances (a proxy for in-work poverty), with those finding it 'difficult' or 'very difficult' to manage displaying lower levels of job control. This finding highlights the importance of 'spill-over' effects between personal and work lives, and the potential impact of low wages within the sector, particularly among women, who constitute the majority of this workforce (SfC, 2016). This could link to arguments about the increased vulnerability of LTC workers, as a high proportion are women with low level qualifications, many of whom also have their own caring responsibilities (Baines and Cunningham, 2011).

The bivariate analysis shows that care workers employed primarily in care homes had significantly lower levels of job insecurity, compared with those not working primarily in care homes ( $\mu=5.5$ vs. 6.3 ). Frontline care workers working primarily in homecare, providing care in people's own homes, displayed significantly higher levels of both job demand and job insecurity ( $\mu=35.9$ and 6.2 vs. $\mu=33.3$ and 5.7 respectively). These differences may reflect the nature and organisation of work within the two settings. For example, the turnover rate is significantly higher (Hussein, Ismail and Manthorpe, 2016; SfC, 2016) and wages are lower (Hsusein and Manthorpe, 2014) among homecare than care home workers. The significantly higher levels of job demand and job insecurity among homecare workers may relate to the casualisation and fragmentation of their work, including the greater use of zero-hours 
contracts in the homecare industry than in residential care settings (Hussein, 2017; Grimshaw and Rubery, 2012; Rubery et al, 2011).

The relationship between different job aspects, and their impact on workers, are not straightforward as some dimensions may compensate for others, mitigating the negative effects of increased work pressure (for example). To assess this, we adopted the Karasek JDC model as it identifies the two crucial job aspects of control and demand and examines the dynamic relationship between them (Karasek et al, 1998). Using a large sample of care workers in England, we were able to categorise these into the four categories within the model: those displaying 'low', 'passive', 'active' and 'high' strain within their job experience ('active' job experience being the most desired, and 'high' strain job experience posing the greatest risk on workers' physical and emotional health). The analysis showed that more than a third of the sample had a high strain job experience (35\%); this is the group most at risk of negative health and employment outcomes, including cardiovascular disease, mental health problems and higher probabilities of job quitting (Elovainio et al, 2005; Hoogendoorn et al, 2000; Warr, 1990). On the other hand, 13\% of our sample displayed the characteristics of a 'low strain' job experience, with high levels of control, and minimal work demands. In the literature, little is reported about the wider implications of low strain job experiences, although some analysis suggests this kind of work environment may lead to boredom and deskilling, and to negative health consequences (Dwyer and Ganster, 1991). One third of the sample experienced 'active' jobs, the most desirable state within the JDC model.

The results of the multinomial regression model (Table 5) show that, in the LTC sector, some job and personal characteristics are associated with the likelihood of having a high strain job experience: age; level of social support at work; nature of work (mostly hands on care, or mainly hands on care with some administrative tasks); and belonging to a trade union were all 
found to be significantly associated with having a high strain (versus a low strain) job experience. Other factors, such as the worker's ability to manage their own finances; place of work; and the survey time point showed some associations with having a high strain job experience. When other factors were controlled for, personal characteristics such as gender, ethnicity or nationality were not significantly associated with having a high strain job experience.

Consistent with the JDC model, we find that high level of social support received at work is associated with lower probability of having a high strain job experience $(\mathrm{OR}=0.74 ; p<0.001)$. Those who reported higher levels of social support (from co-workers and supervisors combined) were significantly more likely to have low job strain than those with any other job experience. The Karasek social support scale captured elements related to the supervisor and co-workers' role in ensuring both the delivery of work and the welfare of colleagues. For example, it collected workers' views on how far their supervisors are concerned with their welfare and paid attention to what they say, as well as how they help in getting the job done and ensured people work well together. These findings are consistent with other research, on nursing staff, where a reported high level of social support at work was significantly associated with a lower incidence of stress and burnout (Woodhead et al, 2016). This is an important finding, particularly in the context of an increased use of homecare services and reduced opportunities for homecare workers to engage with or receive social support from supervisors or co-workers (McGann et al, 2016). The current analysis did not show that homecare workers were significantly more likely to experience high strain jobs when other variables were controlled for, however, homecare workers were significantly more likely to have passive job experiences (low job control and job demand) than low strain jobs. On the other hand, care home workers were found to have a higher probability of being in high strain than in low strain jobs, albeit with borderline significance $(\mathrm{OR}=1.70, p=0.065)$. These 
findings warrant further investigation to understand what other support mechanisms are available to LTC workers in both settings, and how they interact with work and health outcomes, such as job satisfaction and general wellbeing.

LTC workers with a combination of hands-on care and administrative tasks were significantly more likely to experience high job strain than those whose duties primarily involved hands-on care duties. This finding could be explained, conceptually, in relation to the documented intrinsic nature of care work and the reported motives which lead people to work in caring jobs. A number of studies indicate that most care workers choose this work to make a difference and to help others (Rubery et al, 2011; Spenceley et al, 2015) and that this is usually achieved in periods of direct contact with care users, interactions in which an emotional reward is gained. The findings in the current study suggest that when direct caring work is interrupted by administrative work, workers are likely to experience higher job strain than when their work is predominantly 'hands-on' with clients. This finding is quite important, in the context of the increased pressure on funding of care services, and reported reductions in contact time with users, especially in homecare settings (Rubery et al, 2015).

The results relating to trade union membership may at first seem counter-intuitive (workers belonging to trade unions have higher levels of job demand and job control, as well as higher levels of job insecurity). The regression model showed that they are also significantly more likely to have high strain or active job experiences than low strain job experiences $(\mathrm{OR}=2.86$ and $4.64 ; p<0.001$ respectively). These differences are likely to be linked to the characteristics of the group of workers who are more likely to be members of trade unions. Murphy and Turner (2014) argue that to mobilise unionisation of non-standard workers such as care workers, three conditions are needed: 'grievances, blame attribution and efficacy beliefs'. Thus, within a low-density unionised occupation such as care work, those seeking trade union 
membership are likely to be suffering from some sort of injustice within their workplace, which could explain the higher levels of demand observed in this study.

In this analysis we used the question of 'how well workers manage their own finances' as a proxy for financial pressure and potentially for in-work poverty. This variable was significantly associated with several outcomes in the study, including levels of job control and which quadrant of the job experience workers fell into. The multinomial regression model indicated that LTC workers who found their finances difficult to manage had significantly higher probability of experiencing high strain and passive jobs, compared with those who managed their finance well / alright. This finding raises concerns about the relationship between progressive austerity measures and persistent low wages in the LTC sector and the greater prevalence of high strain jobs, with potential implications for workers' wellbeing and quality of life (Hussein, 2017; Baines \& Cunningham, 2011; Grimshaw \& Rubery, 2012).

An interesting finding of the current analysis relates to the small effect which the personal characteristics of LTC workers appears to have on their job experience. Only age was found to be associated with the type of job experience observed among LTC workers, with older workers significantly more likely to have low strain jobs. When other work environment factors are accounted for, gender, ethnicity and nationality did not appear to have any impact on the workers' job experience. Previous research on migrant LTC workers in England, including migrant men, has identified the importance of external factors, such as personal social networks and other life goals, in shaping workers' specific experience of care work (Christensen, Hussein and Ismail, 2017; Hussein and Christensen, 2017). It is likely that other factors, not captured in this study, are involved in reducing the effect of personal characteristics on job strain. Equally, it could be that environmental factors, such as social 
support and nature of work, are more important in predicting the job experience of LTC workers.

Care workers responding in T2 (2012-13) were significantly more likely to experience active jobs, or to have a high strain job experience, than those responding in T1 (2010-11). (The latter is at borderline significance, however: $\mathrm{OR}=2.17$ and $1.69 ; p=0.008$ and $p=0.079$ respectively). This may reflect wider changes in the organisation and funding of social care in England between these time periods, which include reductions in local and central funding and increases in outsourcing and marketisation (Grimshaw and Rubery, 2012). Due to the relatively short time between $\mathrm{T} 1$ and $\mathrm{T} 2$, however, it is not possible to establish a direct relationship between the two observations.

\section{Conclusion}

LTC workers provide intimate and personal care to growing numbers of older people and adults with long term care needs and disabilities. Within the context of population ageing and growing demand for social care, it is important to understand the job dynamics of this workforce and their potential implications for individual workers. Alongside growth in demand, social care has also been changed dramatically in England in the past decade by outsourcing and marketisation policies, continuing austerity measures and reductions in public funding. The current study highlights care workers' vulnerability to high strain job experiences, with potential risks to their own health and wellbeing, and the crucial role social support at work plays in reducing the probability of high strain in these jobs. This finding indicates the need for effective organisational strategies. These should aim to ensure not only that the working conditions are adequate, but also that good quality supervisory and coworker support is available. Social support needs to be embedded in practice, as an essential part of LTC service delivery, to safeguard workers' wellbeing and ensure the quality of care 
delivery. Workers who find their finances difficult to manage, and those who provide both hands-on care and administrative tasks, were at higher risk of job strain. Strategic attention should be given to life-work balance and the spill-over of stress between home and work to support LTC workers. Since trade union membership appears to be more prevalent among LTC workers suffering from work related stress, strategies are also needed to increase membership and ensure LTC workers have a collective voice, and bargaining power, within the dynamic social care context.

\section{Acknowledgment and Disclaimer}

This work was supported by the English Department of Health and Social Care, Policy Research Programme under grant number [DH/035/0095]. The views expressed are those of the author alone and do not necessarily represent that of the Department of Health and Social Care. I thank the Longitudinal Care Work Study (LoCS) research team including Jess Harris, Jo Moriarty, Jill Manthorpe, Martin Stevens and Kritika Samsi. 


\section{References}

Anderson, N. and Hughes, K. (2010) The business of caring: Women's self-employment and the marketization of care, Gender, Work and Organization, 17: 381-405.

Baines, D. and Cunningham, I. (2011) 'White knuckle care work': violence, gender and new public management in the voluntary sector, Work Employment and Society, 25: 760-76. Bakker, A. and Demerouti, E. (2007) The Job Demands-Resources model: state of the art, Journal of Managerial Psychology, 22 (3): 309-28.

Brotheridge, C. and Grandey, A. (2002) Emotional labor and burnout: Comparing two perspectives of 'people work', Journal of Vocational Behavior, 60: 17-39.

Christensen, K., Hussein, S. and Ismail, M. (2017) Migrant intelligence shaping work destination choice: the case of long-term care work in the United Kingdom and Norway. European Journal of Aging. 14(3): 219-232.

Colombo, F, Llena-Nozal, A, Mercier, J. and Tjadens, F. (2011) Help wanted? Providing and paying for long-term care, OECD Health Policy Studies, OECD Publishing.

Dwyer, D.J. and Ganster, D. C. (1991) The effects of job demands and control on employee attendance and satisfaction, Journal of Organizational Behavior, 12: 595-608.

Elovainio, M., Forma, P., Kivimäki, M., Sinervo, T., Sutinen, R. and Laine, M. (2005) Job demands and job control as correlates of early retirement thoughts in Finnish social and health care employees, Work \& Stress, 19: 84-92.

Evans, S., Huxley, P., Gately, C., Webber, M., Mears, A., Pajak, S., Medina, J., Kendall, T. and Katona, C. (2006) Mental health, burnout and job satisfaction among mental health social workers in England and Wales, British Journal of Psychiatry, 188: 75-80.

Gama, G., Barbosa, F. and Vieira, M. (2014) Personal determinants of nurses' burnout in end of life care. European Journal of Oncology Nursing, 18: 527-33. 
Grimshaw, D. and Rubery, J. (2012) The end of the UK's liberal collectivist social model? The implications of the Coalition Government's policy during the austerity crisis. Cambridge Journal of Economics, 36: 105-26.

Hallqvist, J., Diderichsen, F., Theorell, T., Reuterwall, C. and Ahlbom, A. (1998) Is the effect of job strain on myocardial infarction risk due to interaction between high psychosocial demands and low decision latitude? Results from Stockholm Heart Epidemiology Program (SHEEP), Social Science Medicine, 46: 1405-15:

Himmelweit, S. (2014) The marketisation of care before and during austerity. Paper presented at the IIPPE Annual Conference, Naples, 16-18 September 2014. Hoogendoorn, W., van Poppel, M., Bongers, P., Koes, B. and Bouter, L. (2000) Systematic review of psychosocial factors at work and private life as risk factors for back pain. Spine, 25: $2114-25$.

Hussein, S. (2017) 'We don't do it for the money'... The scale and reasons of poverty-pay among frontline long term care workers in England. Health and Social Care in the Community. 25(6): 1817-1826.

Hussein, S. and Christensen, K. (2017) Migration, gender and low-paid work: on migrant men's entry dynamics into the feminised social care work in the UK. Journal of Ethnic and Migration Studies. 43(5): 749-765.

Hussein, S. and Manthorpe J. (2014) Structural marginalisation among the long-term care workforce in England: evidence from mixed-effect models of national pay data. Ageing and Society. 34(1): 21-41.

Hussein, S., Ismail, M. and Manthorpe, J. (2016) Changes in turnover and vacancy rates of care workers in England from 2008 to 2010: Panel analysis of national workforce data. Health $\&$ Social Care in the Community. 24(5): 547-556. 
Hussein, S., Manthorpe, J., Ridley, J., Austerberry, H., Ferrelly, N., Larkins, C., Bilson, A. and Stanley, N. (2014) Independent Children's Social Work Practice Pilots: Evaluating Practitioners' Job Control and Burnout, Research on Social Work Practice. 24(2): 224-234. Hussein, S., Moriarty, J. Stevens, M., Sharpe, E. \& Manthorpe, J. (2014) Organisational factors, job satisfaction and intention to leave among newly qualified social workers in England, Social Work Education, An International Journal. 33 (3): 381-396.

Karasek, R. (1985) Job Content Questionnaire and user's guide, Lowell, England: University of Massachusetts Lowell.

Karasek, R., Brisson, C., Kawakami, N., Houtman, I., Bongers, P. and Amick, B. (1998) The Job Content Questionnaire (JCQ): An instrument for international comparative assessments of psychosocial job characteristics. Journal of Occupational Health Psychology, 3: 322-55. Karasek, R. A. and Theorell, T. (1990) Healthy work: Stress, productivity and the reconstruction of work life, New York : Basic Books.

Landsbergis, P. and Theorell, T. (1999) Measurement of psychosocial workplace exposure variables. Self-report questionnaires. Occupational Medicine, 15: 163-71.

Research/Migrated-Resources/Documents/H/OTS_Helping_Out.pdf

Manthorpe, J., Harris, J., Hussein, S., Cornes, M. and Moriarty, J. (2014) Evaluation of the social work practices with adults pilots: final report, King's College London, UK: Social Care Workforce Research Unit.

Maslach, C. and Jackson, S. (1984) Patterns of burnout among a national sample of public contact workers, Journal of Health and Human Resource Administration, 7: 189-212. McGann, M., White, K. and Moss, J. (2016) Labour casualization and the psychosocial health of workers in Australia. Work, Employment and Society, DOI: 10.1177/0950017016633022. Milligan, C. and Wiles, J. (2010) Landscapes of care, Progress in Human Geography, 34: $736-54$. 
Murphy, C. and Turner, T. (2014) Organising non-standard workers: union recruitment in the Irish care sector, Industrial Relations Journal, 45: 373-88.

Office for National Statistics (2017) UK labour market: January 2017, Estimates of employment, unemployment, economic inactivity and other employment-related statistics for the UK. Statistical Bulletin: ONS.

https://www.ons.gov.uk/employmentandlabourmarket/peopleinwork/employmentandemploye etypes/bulletins/uklabourmarket/jan2017

Rubery, J., Grimshaw, D., Hebson, G. and Ugarte, S.M. (2015). 'It's all about time': Time as contested terrain in the management and experience of domiciliary care work in England.

Human Resource Management, 54: 753-72.

Rubery, J., Hebson, G., Grimshaw, D., Carroll, M., Smith, L., Marchington, L. and Ugarte, S. (2011) The recruitment and retention of a care workforce for older people, Manchester, University of Manchester.

Sargent, L. and Terry, D. (2000) The moderating role of social support in Karasek's job strain model, Work \& Stress, 14 (3): 245-61.

SfC [Skills for Care] (2016). The state of the adult social care sector and workforce in England, Leeds: Skills for Care.

Skirrow, P. and Hatton, C. (2007) 'Burnout'amongst direct care workers in services for adults with intellectual disabilities: A systematic review of research findings and initial normative data. Journal of Applied Research in Intellectual Disabilities, 20: 131-44.

Spenceley, S., Witcher, C., Hagen, B., Hall, B. and Kardolus-Wilson, A. (2015) Sources of moral distress for nursing staff providing care to residents with dementia. Dementia, online DOI: $10.1177 / 1471301215618108$ [ichepi]

Van der Doef, M. and Maes, S. (1999) The Job Demand-Control (-Support) Model and psychological well-being: A review of 20 years of empirical research, Work \& Stress, 13 (2): $87-114$. 
Varcoe, C., Pauly, B., Storch, J., Newton, L. and Makaroff, K. (2012) Nurses' perceptions of and responses to morally distressing situations. Nursing Ethics, 19: 488-500.

Warr, P. (1990) Decision latitude, job demands and employee well-being. Work \& Stress, 4: 285-94.

Woodhead, E., Northrop, L. and Edelstein, B. (2016) Stress, social support, and burnout among long-term care nursing staff, Journal of Applied Gerontology, 35: 84-105.

Wilberforce, M., Jacobs, S., Challis, D., Manthorpe, J., Stevens, M., Jasper, R., Fernandez, J.L., Glendinning, C., Jones, K., Knapp, M., Moran, N. and Netten, N. (2014) Revisiting the causes of stress in social work: sources of job demands, control and support in personalised adult social care, British Journal of Social Work, 44: 812-30.

Yeandle, S., Chou, Y.C., Fine, M., Larkin, M. and Milne, A. (2017) 'Care and caring: interdisciplinary perspectives on a societal issue of global significance', International Journal of Care and Caring, 1(1): 3-25. 
Figure 1 The Job Demand Control (JDC), adopted from Karasek (1979)

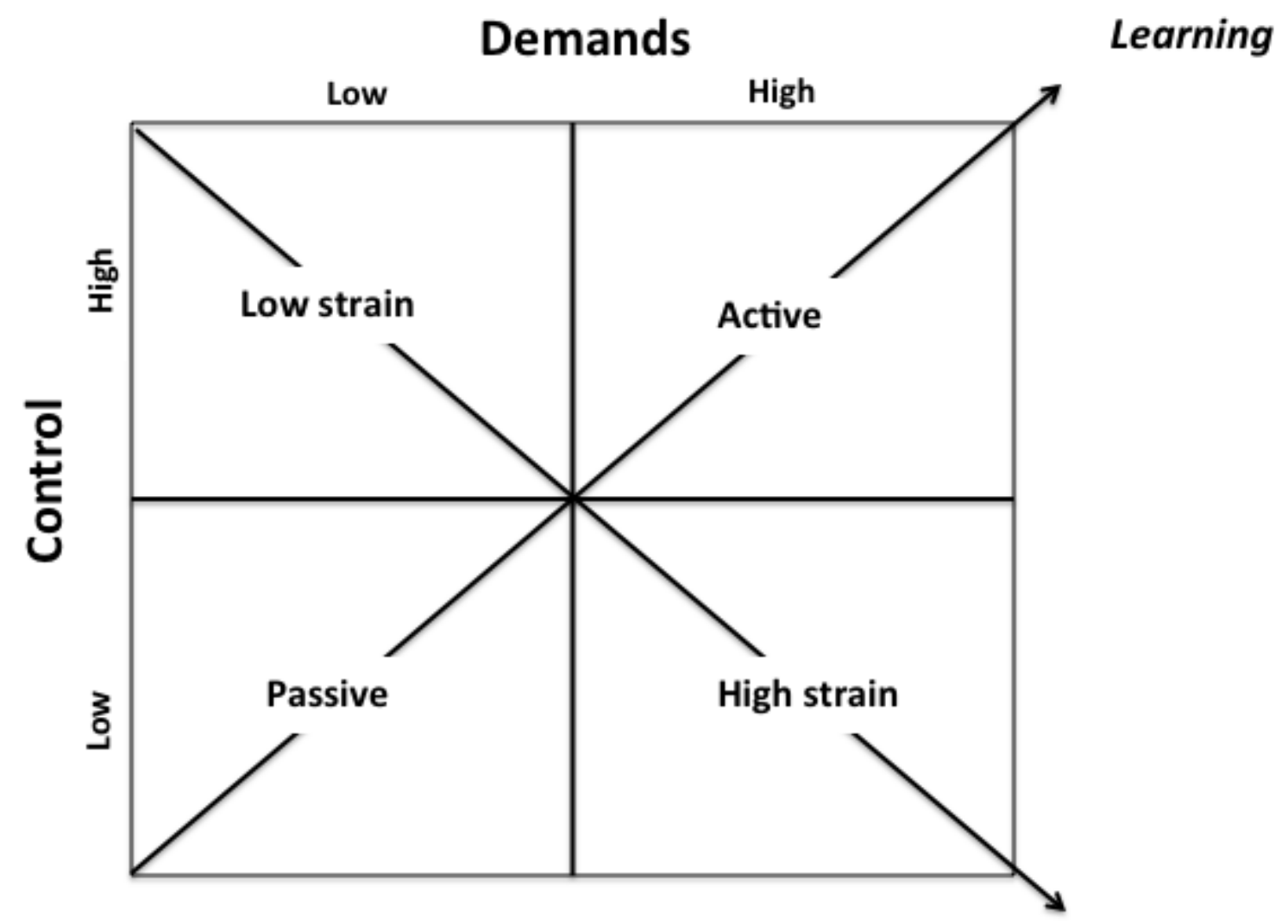

Strain 
Figure 2 Distribution of participants in the survey according to level of job demand and control classified according to the JDC model

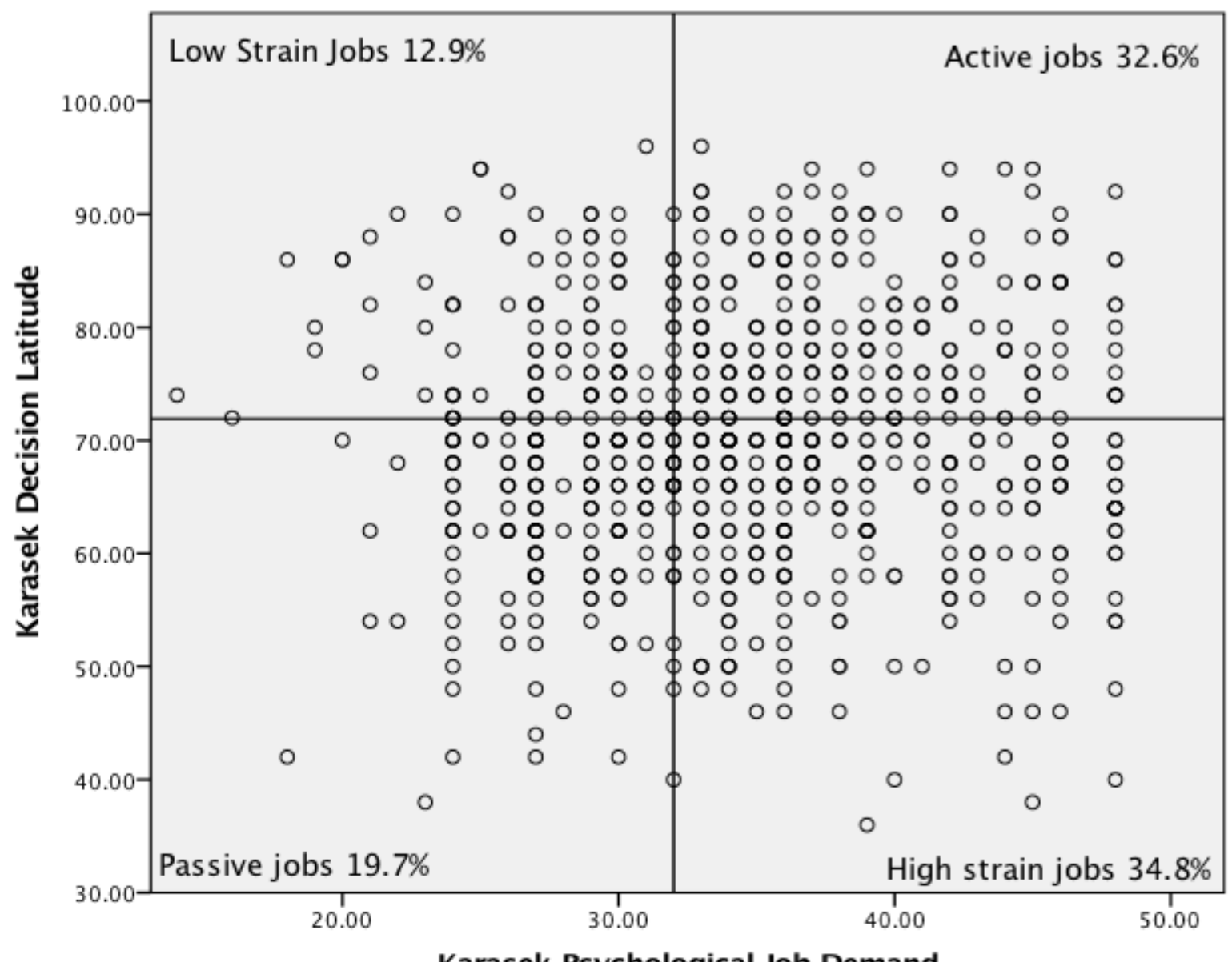

Karasek Psychological Job Demand 
Table 1 Profile of participants to the Study A's survey

\begin{tabular}{|c|c|}
\hline Participants' characteristics & Statistics \\
\hline Age: Mean $(\mu)$ & 44.4 \\
\hline Standard deviation $(\sigma)$ & 9.9 \\
\hline Valid N & 991 \\
\hline \multicolumn{2}{|l|}{ Gender } \\
\hline Man & $19.1 \%$ \\
\hline Woman & $80.9 \%$ \\
\hline Valid N & 991 \\
\hline \multicolumn{2}{|l|}{ Nationality } \\
\hline British & $85.9 \%$ \\
\hline Migrant & $14.1 \%$ \\
\hline Valid N & 830 \\
\hline \multicolumn{2}{|l|}{ Ethnicity } \\
\hline White British & $81.0 \%$ \\
\hline BME & $19.0 \%$ \\
\hline Valid & 830 \\
\hline \multicolumn{2}{|l|}{ Nature of Work } \\
\hline All or mostly direct care work & $54.2 \%$ \\
\hline Combination of care and administrative work & $45.8 \%$ \\
\hline Valid N & 991 \\
\hline \multicolumn{2}{|l|}{ Main Place of work $\dagger$} \\
\hline Care Home (including nursing homes) & $45.2 \%$ \\
\hline Homecare & $43.8 \%$ \\
\hline Valid N & 991 \\
\hline \multicolumn{2}{|l|}{ Survey time } \\
\hline T1 (2010-11) & $68.6 \%$ \\
\hline T2 (2012-13) & $31.4 \%$ \\
\hline Valid N & 991 \\
\hline
\end{tabular}

$\uparrow$ Multiple options were allowed (the same worker might be working in two settings or more) 
Table 2 Karasek JCQ scales, decision latitude, psychological job demand, job insecurity and social support by social care staff individual characteristics, Study A

\begin{tabular}{|c|c|c|c|c|c|}
\hline & & & Karase & CQ Scales & \\
\hline Individual Characteristics & & $J o b$ & Job Demand & $J o b$ & Social Support \\
\hline Gender & & & & & \\
\hline Male & & & & & \\
\hline & $\mu$ & 69.9 & 33.8 & 6.1 & 24.2 \\
\hline & $\mathrm{N}$ & 154 & 157 & 154 & 153 \\
\hline & $\sigma$ & 10.8 & 6.4 & 2.0 & 3.8 \\
\hline Female & & & & & \\
\hline & $\mu$ & 70.6 & 34.7 & 5.9 & 24.4 \\
\hline & $\mathrm{N}$ & 653 & 655 & 664 & 651 \\
\hline & $\sigma$ & 10.8 & 6.6 & 2.1 & 3.8 \\
\hline Nationality & & & & & \\
\hline British & & & & & \\
\hline & $\mu$ & 70.3 & 34.6 & 6.0 & 24.4 \\
\hline & $\mathrm{N}$ & 716 & 719 & 719 & 707 \\
\hline & $\sigma$ & 10.9 & 6.6 & 2.1 & 3.8 \\
\hline Migrant & & & & & \\
\hline & $\mu$ & 70.3 & 34.1 & 5.8 & 24.2 \\
\hline & $\mathrm{N}$ & 133 & 135 & 135 & 135 \\
\hline & $\sigma$ & 10.2 & 6.7 & 2.0 & 3.5 \\
\hline Ethnicity & & & & & \\
\hline White British & & & & & \\
\hline & $\mu$ & 70.5 & 34.5 & 5.9 & 24.4 \\
\hline & $\mathrm{N}$ & 639 & 642 & 651 & 638 \\
\hline & $\sigma$ & 11.0 & 6.5 & 2.1 & 3.7 \\
\hline Black and mi & & & & & \\
\hline & $\mu$ & 69.6 & 34.4 & 6.0 & 23.8 \\
\hline & $\mathrm{N}$ & 151 & 153 & 151 & 150 \\
\hline & $\sigma$ & 10.3 & 6.9 & 2.1 & 3.5 \\
\hline Managing own finance & & $* * *$ & & & \\
\hline
\end{tabular}




\begin{tabular}{|c|c|c|c|c|c|}
\hline \multicolumn{6}{|c|}{$\begin{array}{l}\text { Living very comfortably or doing } \\
\text { alright }\end{array}$} \\
\hline & $\mu$ & 72.3 & 34.7 & 5.7 & 24.6 \\
\hline & $\mathrm{N}$ & 337 & 344 & 347 & 344 \\
\hline & $\sigma$ & 10.4 & 6.5 & 1.9 & 3.5 \\
\hline \multicolumn{6}{|c|}{ Just about getting by } \\
\hline & $\mu$ & 69.4 & 34.3 & 6.0 & 24.3 \\
\hline & $\mathrm{N}$ & 278 & 277 & 280 & 274 \\
\hline & $\sigma$ & 11.1 & 6.6 & 2.2 & 3.8 \\
\hline \multicolumn{6}{|c|}{ Finding it quite or very difficult } \\
\hline & $\mu$ & 68.4 & 34.4 & 6.0 & 24.0 \\
\hline & $\mathrm{N}$ & 186 & 185 & 185 & 179 \\
\hline & $\sigma$ & 11.0 & 6.8 & 2.2 & 3.9 \\
\hline \multirow[t]{3}{*}{ Total: } & $\mu$ & 70.3 & 34.5 & 5.9 & 24.4 \\
\hline & $\mathbf{N}$ & 849 & 854 & 854 & 842 \\
\hline & $\sigma$ & 10.8 & 6.6 & 2.1 & 3.7 \\
\hline
\end{tabular}

* Significantly different at $\mathrm{p}<0.05 ; * * \mathrm{p}<0.005 ; * * * \mathrm{p}<0.001 ; \ddagger$ Sub-groups may not add to total number due to missing values 
Table 3 Karasek JCQ scales, decision latitude, psychological job demand, job insecurity and social support by social care staff job characteristics, Study A

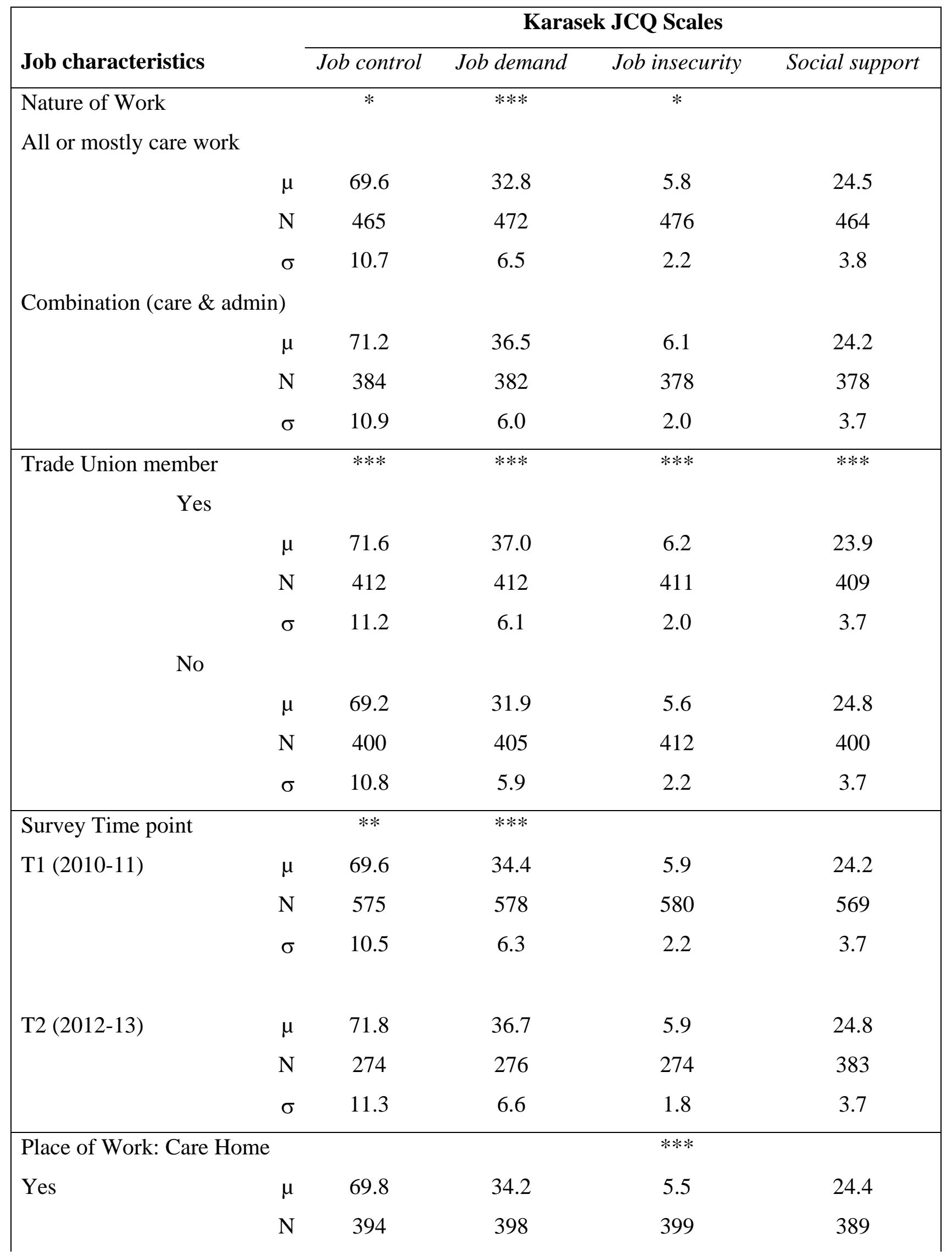




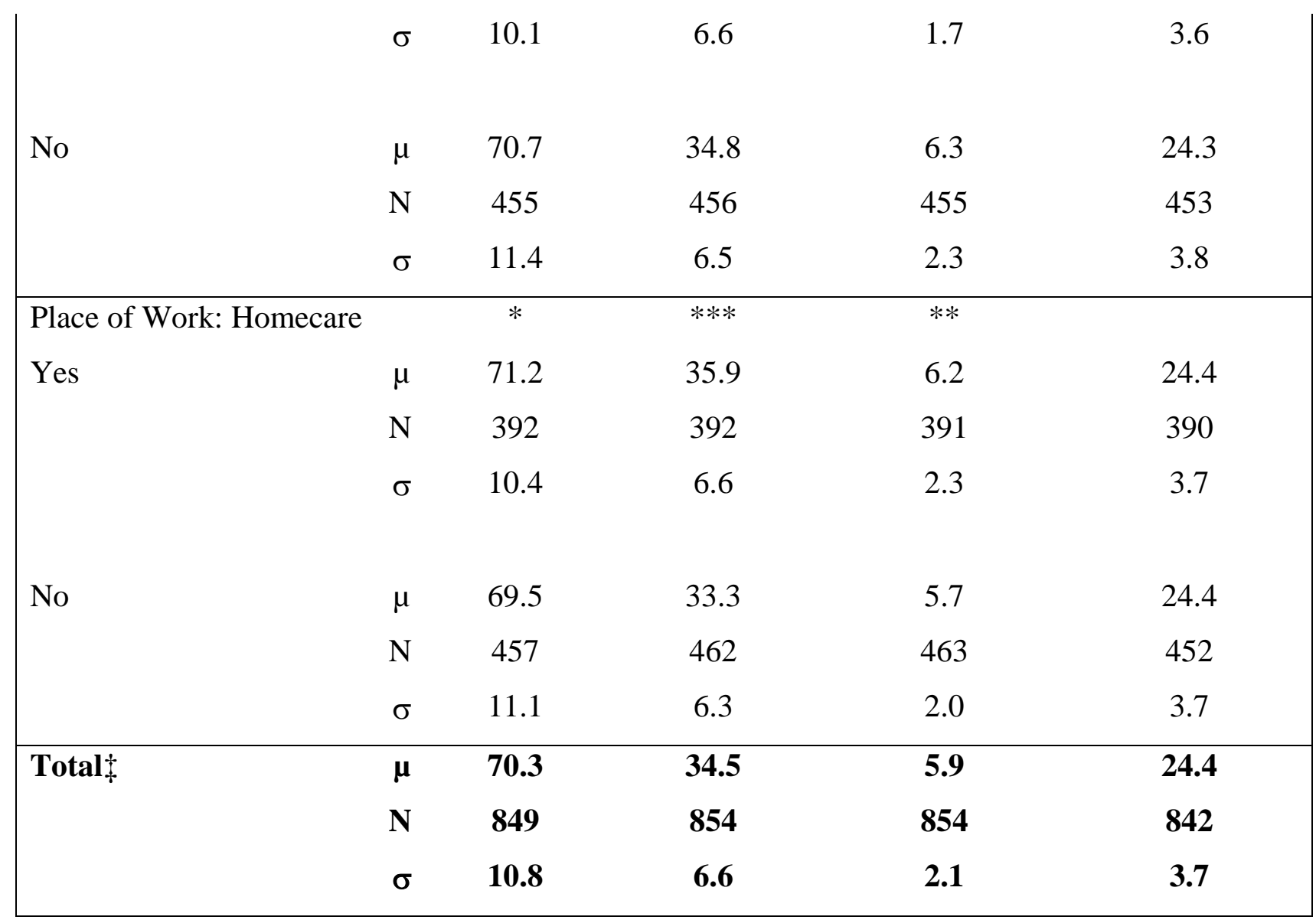

* Significantly different at $p<0.05 ; * * p<0.005$; *** $p<0.001 ;$ \$ Sub-groups may not add to total number due to missing values 
Table 4 Classifications of LTC according the four groups of Karasek JDC model according to selected individual and workplace characteristics

\begin{tabular}{|c|c|c|c|c|c|}
\hline Individual and & Class & cation acc & ng to JD & & Valid N \\
\hline workplace & Low Strain & Passive & Active & High & \\
\hline Characteristics & $\%$ & $\%$ & $\%$ & Strain & \\
\hline & & & & & \\
\hline Gender & & & & & \\
\hline Male & 14.3 & 20.8 & 29.2 & 35.7 & 202 \\
\hline Female & 13.0 & 18.2 & 33.5 & 33.5 & 863 \\
\hline Age* & & & & & \\
\hline$\mu$ & 47.0 & 42.5 & 44.5 & 45.0 & 44.6 \\
\hline$\sigma$ & 10.5 & 11.2 & 9.1 & 10.2 & 10.2 \\
\hline Ethnicity & & & & & \\
\hline White & 13.3 & 19.6 & 33.1 & 34.0 & 626 \\
\hline $\mathrm{BME}$ & 14.1 & 16.8 & 30.2 & 38.9 & 149 \\
\hline Nationality & & & & & \\
\hline British & 12.5 & 19.9 & 32.8 & 34.8 & 704 \\
\hline Migrant & 15.4 & 18.5 & 31.5 & 34.6 & 130 \\
\hline Place of Work & & & & & \\
\hline Care homes & 11.7 & 21.7 & 30.8 & 35.8 & 383 \\
\hline Homecare $* * *$ & 12.9 & 12.4 & 36.3 & 38.7 & 388 \\
\hline Nature of work $* * *$ & & & & & \\
\hline All or mostly care & 15.9 & 28.3 & 26.0 & 29.8 & 453 \\
\hline $\begin{array}{r}\text { Combination of care \& } \\
\text { admin }\end{array}$ & 9.4 & 9.4 & 40.4 & 40.7 & 381 \\
\hline Trade Union Membership & & & & & \\
\hline Yes & 8.0 & 8.5 & 42.8 & 40.6 & 411 \\
\hline No & 18.9 & 30.3 & 21.2 & 29.5 & 386 \\
\hline Managing own finance** & & & & & \\
\hline Alright/very well & 14.7 & 15.0 & 36.9 & 33.3 & 333 \\
\hline Just about & 14.0 & 18.5 & 29.9 & 37.6 & 271 \\
\hline Difficult/very difficult & 9.8 & 28.4 & 26.8 & 35.0 & 183 \\
\hline
\end{tabular}




\begin{tabular}{|lr|c|c|c|c|c|}
\hline \multicolumn{2}{|l|}{ Karasek Social Support Score $* * *$} & & & & \\
\hline & $\mu$ & 26.7 & 23.9 & 25.1 & 22.9 & 24.3 \\
\hline \multicolumn{2}{|l|}{ Survey time } & 4.0 & 3.5 & 3.7 & 3.2 & 3.8 \\
\hline & $\mathrm{T} 1$ & 14.5 & 23.0 & 28.2 & 34.3 & 560 \\
\hline & $\mathrm{T} 2$ & 9.9 & 12.8 & 41.6 & 35.8 & 274 \\
\hline All participants & & $\mathbf{1 2 . 9}$ & $\mathbf{1 9 . 7}$ & $\mathbf{3 2 . 6}$ & $\mathbf{3 4 . 8}$ & $\mathbf{8 3 4}$ \\
\hline
\end{tabular}

* Significantly different at $p<0.05 ; * * p<0.005 ; * * * p<0.001$ (using F or $\chi^{2}$ tests) 
Table 5 Results of a multinomial regression model of the type of care workers' job experience according to different personal and job characteristics

\begin{tabular}{|c|c|c|c|c|c|c|c|c|c|c|c|c|}
\hline \multirow{3}{*}{$\begin{array}{l}\text { Independent variables in the } \\
\text { model }\end{array}$} & \multicolumn{4}{|c|}{ Passive vs. Low strain } & \multicolumn{4}{|c|}{ Active vs. Low strain } & \multicolumn{4}{|c|}{ High strain vs. Low strain } \\
\hline & \multirow[t]{2}{*}{ P-value } & \multirow[t]{2}{*}{$\begin{array}{l}\text { Odds } \\
\text { Ratio }\end{array}$} & \multicolumn{2}{|c|}{$\begin{array}{c}\text { Confidence } \\
\text { Interval }\end{array}$} & \multirow[t]{2}{*}{ P-value } & \multirow[t]{2}{*}{$\begin{array}{l}\text { Odds } \\
\text { Ratio }\end{array}$} & \multicolumn{2}{|c|}{$\begin{array}{c}\text { Confidence } \\
\text { Interval }\end{array}$} & \multirow[t]{2}{*}{ P-value } & \multirow[t]{2}{*}{$\begin{array}{l}\text { Odds } \\
\text { Ratio }\end{array}$} & \multicolumn{2}{|c|}{$\begin{array}{c}\text { Confidence } \\
\text { Interval }\end{array}$} \\
\hline & & & $2.5 \%$ & $97.5 \%$ & & & $2.5 \%$ & $97.5 \%$ & & & $2.5 \%$ & $97.5 \%$ \\
\hline Age & 0.007* & 0.97 & 0.94 & 0.99 & $\mathrm{0.006}^{*}$ & 0.97 & 0.94 & 0.99 & $0.024^{*}$ & 0.97 & 0.95 & 1.00 \\
\hline Social Support (Karasek) & $<0.001^{\S}$ & 0.79 & 0.73 & 0.86 & $\mathbf{0 . 0 0 2}^{\dagger}$ & 0.89 & 0.83 & 0.96 & $<0.001^{\S}$ & 0.74 & 0.68 & 0.80 \\
\hline \multicolumn{13}{|l|}{ Managing own finance } \\
\hline Well/alright vs. difficult & $0.007^{*}$ & 0.35 & 0.16 & 0.75 & 0.299 & 0.68 & 0.33 & 1.41 & $\underline{0.084}$ & 0.53 & 0.26 & 1.09 \\
\hline Just about vs. difficult & 0.098 & 0.52 & 0.24 & 1.13 & 0.651 & 0.84 & 0.39 & 1.79 & 0.456 & 0.75 & 0.35 & 1.59 \\
\hline Nature: Hands-on vs. comb. & 0.107 & 1.67 & 0.90 & 3.11 & $0.005^{*}$ & 0.47 & 0.28 & 0.80 & $\mathrm{0.005}^{*}$ & 0.47 & 0.27 & 0.80 \\
\hline Ethnicity: White vs. BME & 0.705 & 1.25 & 0.39 & 4.10 & 0.521 & 0.72 & 0.26 & 1.99 & 0.452 & 0.67 & 0.24 & 1.89 \\
\hline \multicolumn{13}{|l|}{ Main place of work } \\
\hline Care home vs. other & 0.503 & 0.80 & 0.42 & 1.54 & 0.180 & 1.46 & 0.84 & 2.55 & $\underline{0.065}$ & 1.70 & 0.97 & 2.98 \\
\hline Homecare vs. other & $\mathbf{0 . 0 2 8}^{*}$ & 0.48 & 0.25 & 0.92 & 0.698 & 1.11 & 0.65 & 1.91 & 0.367 & 1.29 & 0.74 & 2.24 \\
\hline Nationality: British vs. migrants & 0.611 & 1.37 & 0.41 & 4.61 & 0.333 & 1.66 & 0.59 & 4.67 & 0.356 & 1.64 & 0.57 & 4.68 \\
\hline T2 (2012-13) vs. T1 (2010-11) & 0.594 & 1.20 & 0.61 & 2.38 & $\mathbf{0 . 0 0 8}^{*}$ & 2.17 & 1.22 & 3.85 & $\underline{0.079}$ & 1.69 & 0.93 & 3.13 \\
\hline Union- member: Yes vs. no & 0.122 & 0.59 & 0.30 & 1.15 & $<0.001^{\S}$ & 4.64 & 2.67 & 8.06 & $<0.001^{\S}$ & 2.86 & 1.64 & 5.01 \\
\hline Gender: Men vs. women & 0.438 & 1.32 & 0.66 & 2.65 & 0.553 & 0.82 & 0.43 & 1.57 & 0.985 & 1.01 & 0.53 & 1.92 \\
\hline
\end{tabular}

${ }^{*} \mathrm{P}<0.05 ;{ }^{\dagger} \mathrm{P}<0.005$ and ${ }^{\S} \mathrm{P}<0.001$ (borderline significant underlined) 